\title{
Mapa de unidades geoclimáticas para o Estado do Paraná para uso florestal
}

\author{
Elenice Fritzsons ${ }^{1}$, Luiz Eduardo Mantovani² Marcos Silveira Wrege ${ }^{1}$
}

1Embrapa Florestas, Estrada da Ribeira, Km 111, CP 319, CEP 83411-000, Colombo, PR, Brasil, elenice@cnpf.embrapa.br; wrege@cnpf.embrapa.br;'niversidade Federal do Paraná (UFPR), Centro Politécnico, Jardim das Américas, CP 19001, CEP 81531-990, Curitiba, PR, Brasil, lem@ufpr.br

Resumo - Identificar áreas ecológicas similares quanto ao clima, solos e vegetação apresenta inúmeras utilidades potenciais, desde o planejamento do uso e ocupação da terra, incluindo a produção agrossilvipastoril, até a conservação dos ecossistemas naturais. O objetivo deste trabalho foi o de realizar um zoneamento climático para o Estado do Paraná, assistido por análise estatística e com base em compartimentos geomorfológicos para delimitação das unidades geoclimáticas. Por interpretação da análise de cluster sobre os dados das estações metereológicas, o estado foi dividido, inicialmente, em dois grandes grupos: áreas mais quentes e áreas mais frias. A seguir, por critérios estatísticos dentre as áreas quentes, as áreas litorâneas foram separadas das áreas continentais e, de forma semelhante, foram estabelecidas novas subdivisões. A tabela de pertinência composta para este trabalho, feita a partir da definição das zonas geoclimáticas, apresenta uma grande utilidade, pois possibilita alocar espécies florestais para plantio nas áreas mais adequadas, desde que se conheçam suas exigências climáticas (temperatura mínima, temperatura média, resistência a geadas, déficit hídrico, etc.). Este trabalho poderá ser complementado, no futuro, com a integração de dados de outras estações instaladas no estado e mesmo ser transformado em um zoneamento edafo-climático, com a incorporação das informações sobre os solos, e balanços hídricos da região.

Termos para indexação: Zoneamento florestal, zonas geoclimáticas, clima, floresta.

\section{Geoclimatic unities map of Parana State, Brazil, for forestry}

\begin{abstract}
Identifying areas of similar ecological conditions, such as climate, soils and vegetation have many potential uses, since land use planning, including agroforestry planning, to conservation of natural ecosystems. The objective of this study was to produce a climate zoning chart, supported by statistical analysis and also using geomorphological criteria to define the geoclimatic units. As a result of the interpretation of cluster analysis using metereological data, the Paran State was divided, at first, into two broad groups: hotter areas and colder areas. Among the hotter areas, the coastal areas were separated from continental areas and others divisions were obtained. A relevance table, presented in this paper consists in a great practical tool, because it is useful to allow species to be planted more suitably, since we have the knowledge about the species weather conditions requirements, such as the best minimum and average temperature, frost resistance, drought seasons, etc. This chart may be supplemented with information from others newer climatic stations installed in the Paraná State and can be transformed into edafoclimatic chart, using soils and water balance information.
\end{abstract}

Index terms: Forest zoning, geoclimatic areas, climate, forest plantation.

\section{Introdução}

Identificar áreas ecológicas similares quanto ao clima, solos e vegetação apresenta inúmeras utilidades potenciais, desde o planejamento do uso e ocupação da terra, incluindo a produção agrossilvipastoril, até a conservação dos ecossistemas naturais. Para o setor florestal, um dos aspectos essenciais para o êxito dos reflorestamentos consiste no plantio de espécies de procedências geográficas adequadas ao ambiente das regiões visadas. Deve-se considerar que a escolha correta das espécies a serem utilizadas representa 
uma dificuldade nos países da América Latina, onde o reflorestamento se baseia, principalmente, em espécies exóticas (Golfari et al., 1978). O cultivo de uma espécie em local inadequado pode acarretar diversos problemas, tais como produtividade inferior ao potencial da espécie; elevada susceptibilidade às pragas e doenças; inadaptação geral; produção de madeira com características não adequadas à finalidade do plantio; sensibilidade aos efeitos de geada e deficiência hídrica (Ferreira, 1990).

O zoneamento para espécies florestais é muito importante para o Estado do Paraná, pois dentre as atividades agrossilvopastoris no estado, a produção madeireira responde por $40 \%$ da exportação nacional de madeira plantada, gera cerca de 360 mil postos de trabalho na cadeia produtiva, sendo que há um déficit anual de aproximadamente 53 mil hectares de florestas para atender a demanda no estado, de acordo com Seab (2007).

Em termos de zoneamento para o estado, o Zoneamento Ecológico para Plantios Florestais no Estado do Paraná (Carpanezzi, 1986) é documento de referência e que desde a sua publicação vem sendo especialmente procurado por diversos tipos de usuários. Entretanto, hoje, o estado conta com novas estações meteorológicas e uma maior amplitude de monitoramento das estações mais antigas, o que permite uma melhor identificação de ambientes climáticos diferenciados. Além disso, a facilidade de visualização dos perfis geomorfológicos e climáticos, devido à disponibilidade de imagens aéreas e de satélites meteorológicos, permite que outras informações climáticas, mais precisas, possam ser utilizadas para compor uma outra versão deste zoneamento.

Neste contexto, o trabalho objetiva realizar um zoneamento de unidades climáticas para o Paraná, utilizando dados das estações meteorológicas do estado, assistido por análise estatística e com o emprego de critérios geomorfológicos (ou fisiográficos) e altitudinais, para delimitar as unidades geoclimáticas.

Na metodologia desenvolvida, utilizou-se inicialmente análise estatística multivariada para separar conjuntos de estações climaticamente homogêneas, a exemplo dos trabalhos de Falvo et al. (1996), Tristão et al. (1997), Bernardes (1998), Reis et al. (1999) e Andrade et al. (2000). Mais recentemente, Keller Filho et al. (2005) utilizaram o método de análise de agrupamento para definir áreas pluviometricamente homogêneas no Brasil.
Diniz et al. (2003) também, através da análise estatística multivariada, definiram áreas homogêneas quanto às temperaturas máxima e mínima no Rio Grande do Sul. No exterior, Unal et al. (2003) propuseram uma nova divisão climática para a Turquia utilizando a análise de agrupamento, baseada na temperatura e precipitação. Venkatesh \& Joe (2007), em trabalho realizado na Índia, encontraram três zonas com regimes distintos de precipitação, utilizando a análise de cluster e análise de variância. Williams et al. (2007), em trabalho de ecoregionalização do Estado de Iowa (EUA), utilizaram um conjunto de técnicas que inclui análise multivariada e geoprocessamento.

O procedimento estatístico, que envolve a análise multivariada, agrupa estações similares; entretanto, para delimitar espacialmente os grupos formados por estas estações, podem-se utilizar diversos critérios, desde a geoestatística até a delimitação visual de unidades de paisagens semelhantes (critérios fisiográficos). Neste sentido, tem-se como exemplo os trabalhos da Epagri (2001), onde foram separados conjuntos similares de paisagem, baseado no Guia Geral de Zonificação Agroecológica (FAO, 1997), e que apresenta semelhança ao utilizado por Riché \& Mantovani (1987), Mantovani et al. (1994) e por McNab (1996).

A altitude e o relevo tornam-se aspectos básicos da paisagem para delimitar zonas semelhantes, e foram considerados neste trabalho por meio da incorporação da carta hipsométrica ao sistema. A relação direta da altitude com a temperatura é especialmente importante para as regiões tropicais e subtropicais, em que uma diferença altitudinal de algumas centenas de metros provoca mudanças sensíveis no clima, no solo, na vegetação natural e, consequentemente, na adaptação da biota e na aptidão para certos usos da terra. Em trabalho realizado com as estações meteorológicas do Paraná (Fritzsons et al, 2008a), foram encontradas variações de temperatura entre estações próximas correspondentes a um coeficiente adiabático médio de $-1^{\circ} \mathrm{C}$ por 139 $\mathrm{m}$ (em média). Disto resulta que uma alteração de poucas centenas de metros de altitude pode implicar em diferenças térmicas médias superiores àquelas produzidas por diversos graus de latitude na faixa inter e subtropical. Exposições de relevo aos ventos dominantes também geram situações de barlavento e sotavento que se traduzem em mudanças térmicas e pluviométricas através dos efeitos de Föhn, de chuvas orográficas e sombras pluviais. 


\section{Material e métodos}

Para compor o zoneamento, foi revisto o banco de dados climáticos existente (Fritzsons et al, 2008b), atualizado para dezembro de 2008 (Tabela 1). Foi utilizado o Mapa Fitogeográfico do Estado do Paraná (Maack, 1950), como orientação, tendo em vista seu elevado conteúdo de observações de campo, durante uma época em que a cobertura vegetal do estado se encontrava menos alterada pelo uso em relação aos tempos atuais, refletindo melhor as condições ecológicas de cada região.

A delimitação dos grupos obtidos foi comparada com uma grande coleção de imagens de satélite, tanto voltados para Meteorologia, para checagem da nebulosidade e do estado termal da superfície, como os da série Goes, NOAA, AQUA e TERRA, disponibilizadas respectivamente pelo Instituto Astronômico e Geofísico (IAG-USP), Centro de Pesquisas Meteorológicas e Climáticas Aplicadas à Agricultura (CEPAGRIUNICAMP) e Programa OnEarth do Jet Propulsion Lab JPL/NASA. Imagens de maior resolução também foram utilizadas tais como LANDSAT, ASTER e CBERS, disponibilizadas pelo Instituto Nacional de Pesquisas Espaciais (INPE) e United States Geological Survey (USGS) que evidenciam a sazonalidade do estado fenológico da vegetação ao longo de vários anos. Modelos numéricos de circulação atmosférica foram consultados para vários aspectos climáticos e meteorológicos, sobretudo o Global Forecast System (GFS) da NOAA, o MBAR do Instituto Nacional de Meteorologia (INMET) e o High Resolution Regional Model (HRM) do Serviço Meteorológico Alemão (DWD), usado pelo Centro de Hidrografia da Marinha do Brasil.

Para elaborar o mapa de relevo foram utilizados modelos digitais de elevação originários da missão de mapeamento do relevo terrestre SRTM (Shuttle Radar Topography Mission), desenvolvido pela NASA (National Aeronautics and Space Administration), com resolução espacial (pixel) de $90 \mathrm{~m}$ x $90 \mathrm{~m}$, isto é de três arcos - segundos (3"'). Foi gerada a carta hipsométrica, através do Programa Arc Gis 9. Na digitalização do mapa de unidades geoclimáticas, foi utilizado o Software Spring, versão 4.3, do Instituto Nacional de Pesquisas Espaciais (INPE).

Associado a este zoneamento, foi elaborada uma tabela de pertinência. Nela consta a amplitude de variação de diversos parâmetros climáticos de cada unidade delimitada, permitindo que os usuários, tendo conhecimento das exigências das espécies florestais, possam alocá-las nas unidades climáticas mais apropriadas.

O método para elaboração deste trabalho envolveu basicamente quatro etapas: 1) Construção do banco de dados climáticos; 2) Execução da análise estatística (incluindo a seleção e a interpretação das análises); 3) Delimitação de zonas homogêneas na carta hipsométrica e 4) Construção da tabela de pertinência.

\section{Construção do banco de dados}

Inicialmente, foi composto e atualizado o banco de dados visando contar com o maior número de informações meteorológicas disponíveis no Estado do Paraná, passando, no entanto, pelo crivo de uma análise de coerência e adesão aos padrões meteorológicos de cada região. Na composição do banco de dados, foram utilizadas as séries de dados coletados em 33 estações do Instituto Agronômico do Paraná (Iapar, 2009), 26 estações do Instituto Tecnológico Simepar e 13 estações do INMET no Estado do Paraná (Inmet, 1969; Inmet, 1992). Como apoio, foram observados os dados de 14 estações do Estado de São Paulo, em áreas limítrofes à divisa, e uma estação meteorológica da Epagri, em Santa Catarina.

Deve-se observar que, quanto maior a quantidade de estações climáticas numa determinada unidade geoclimática, melhor caracterizada se torna a unidade. Um amplo período de monitoramento das estações também é importante para boa caracterização das estações. Neste trabalho, a análise estatística foi realizada com estações de maior período de monitoramento e foram utilizadas como suporte as do Simepar, de monitoramento mais recente (desde 1997). 


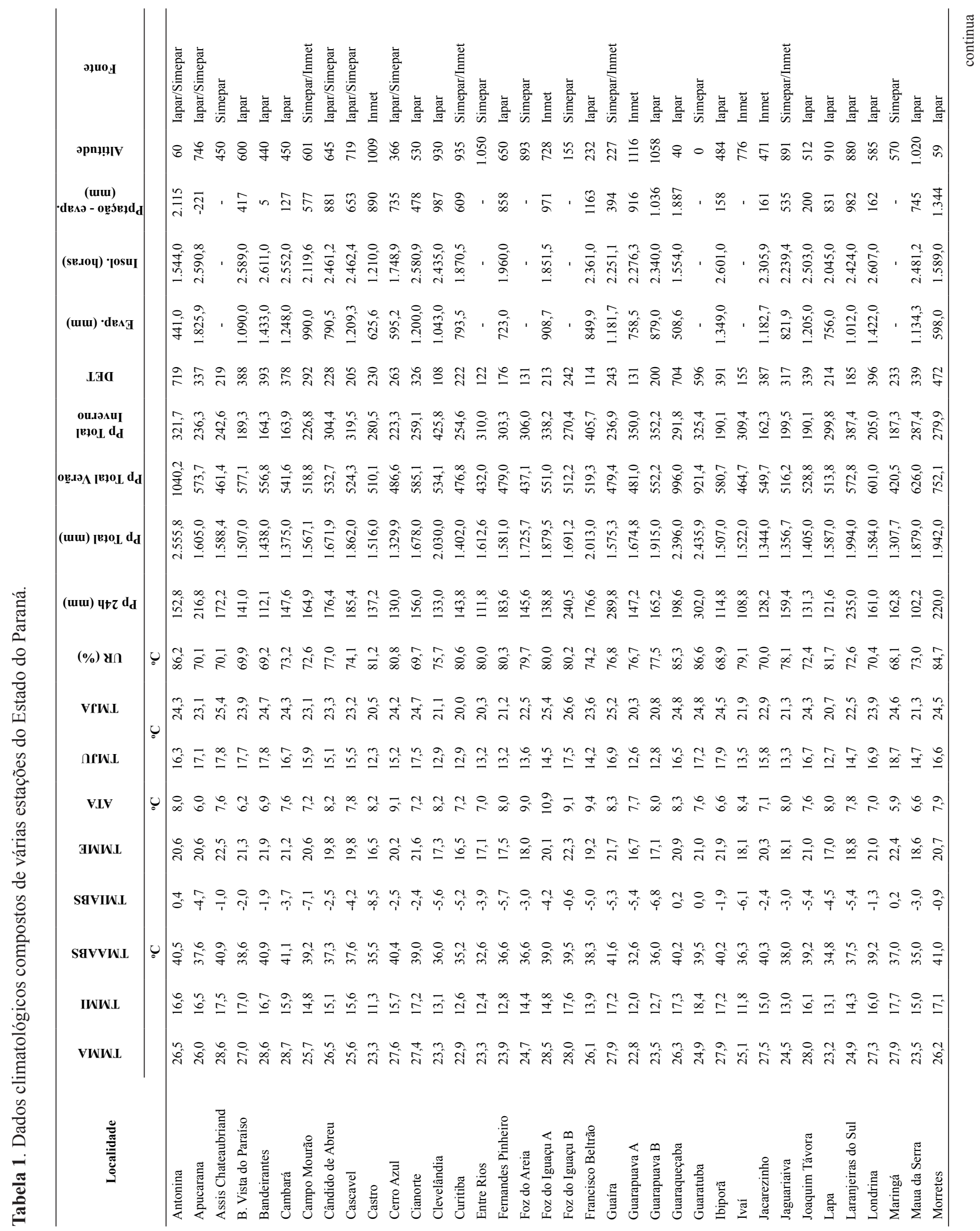




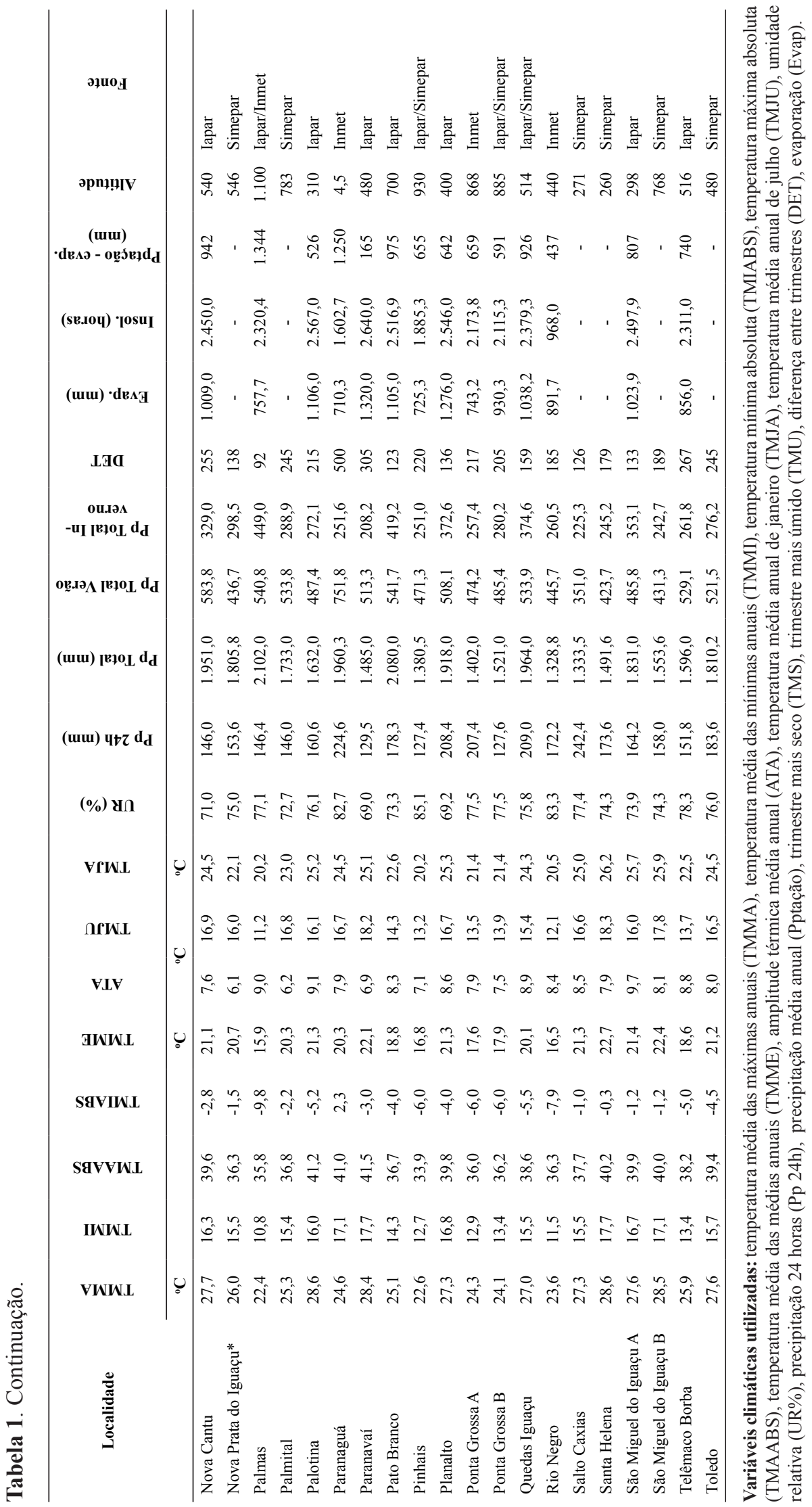


Análise estatística (análise de cluster, método Ward) Aplicou-se a análise de cluster a partir de uma matriz constituída por 58 estações e 16 variáveis: temperatura média das máximas anuais (TMMA), temperatura máxima absoluta do período monitorado (TMAABS), temperatura média das mínimas anuais (TMMI), temperatura mínima absoluta do período monitorado (TMIABS), temperatura média das médias anuais (TMME), amplitude térmica média anual (ATA), temperatura média anual de janeiro (TMJA), temperatura média anual de julho (TMJU), umidade relativa (UR), precipitação total média anual (Pptação), trimestre de inverno (TMS), trimestre mais úmido (TMU), diferença entre trimestres (DET), evaporação total (Evap.), insolação (I) e precipitação menos evaporação (Pptação - Evap).

Inicialmente, aplicou-se a análise para duas combinações de dados. Na primeira, foi aplicada a análise estatística a uma matriz contendo um maior número de estações meteorológicas (56), mas incompletas, isto é, que apresentavam um menor número de variáveis (11), pois nela estavam ausentes evaporação total, insolação e precipitação menos insolação. Em outra, foi priorizado o trabalho com um menor número de estações (44), mas completas, isto é, com todas as variáveis, incluindo evaporação total, insolação e precipitação menos insolação.

O dendrograma com menor número de estações, mais completo, foi o utilizado para definição dos grupos, enquanto que aquele com um maior número de estações foi utilizado como suporte para tomada de decisões, pois permitiu uma observação geral da distribuição dos grupos.

\section{Delimitação de zonas homogêneas}

As classes de relevo foram separadas em cores diferentes em intervalos de 100 em 100 metros de altitude. Como a altitude do Paraná vai desde $2 \mathrm{~m}$ a mais de $1.700 \mathrm{~m}$ de altitude, o número de classes de relevo resultantes foi de 16. A carta hipsométrica foi em seguida impressa em formato A0 e sobre ela foram locadas as estações, considerando latitude e longitude.

Tendo como apoio os grupos formados por meio de análise estatística, os limites entre os grupos foram traçados, observando a continuidade do relevo, latitude, altitude, barreiras orográficas, continentalidade, influência marítima e aspectos fitogeográficos, especialmente com relação à distribuição da FOM (Floresta Ombrófila Mista), uma vez que ela se associa à ocorrência de geadas frequentes e, portanto, aos locais onde ocorrem extremos de temperatura mínima. Nesta etapa foram feitas diversas observações em imagens de satélites meteorológicos e da superfície terrestre para checagem dos limites efetuados. O uso de imagens de satélite foi direcionado no sentido de apoiar as interpretações de limites entre unidades geoclimáticas. Desta forma, as imagens de sensores voltados para os recursos naturais, LANDSAT, SPOT, CBRES, apontaram algumas informações sobre o estado da cobertura vegetal durante as estações do ano. Os sensores mais voltados para fins meteorológicos e hidrológicos como os de média resolução MODIS (Moderate Resolution Imaging Spectroradiometer) portados pelos satélites Terra (EOS AM) e Aqua (EOS PM), além das séries GOES e NOAA de baixa resolução, foram utilizados para identificar alguns padrões de persistência de cobertura nebulosa e de variações térmicas nos solos, tanto noturnas quanto diurnas.

\section{Construção da tabela de pertinência das unidades} geoclimáticas

Esta tabela foi construída observando os grupos formados e delimitados no mapa de unidades geoclimáticas, de forma hierárquica: grandes grupos, grupos, subgrupos, unidades. Em cada tipologia há a amplitude de variação dos parâmetros climáticos, obtidas do banco de dados (Fritzsons et al., 2008b) (Tabela 1). A estação de monitoramento mais antiga foi apresentada em negrito. Alguns subgrupos não estão ligados a estações meteorológicas, mas foram delimitados na carta por apresentarem situações geoambientais mais especificas e, provavelmente, clima diferenciado das unidades vizinhas.

\section{Resultados e discussão}

O dendrograma (Figura 1) ilustra o resultado da análise de agrupamento efetuada com todas as variáveis e, a partir da interpretação hierarquizada, observa-se que:

Em um primeiro nível ou step (primeiro corte), as estações das áreas mais quentes se isolam das estações das áreas mais frias. Analisando as áreas frias, as estações de Palmas, Guarapuava (A e B) e Clevelândia se isolam das demais, sendo que a área de Palmas é a mais diferenciada deste grupo.

Outro grupo, ainda nas áreas frias, é formado pelas estações de Castro, Rio Negro, Porto União, Curitiba, Pinhais, Fernandes Pinheiro, Lapa, Rio Negrinho (SC), Jaguariaíva e Ponta Grossa (A e B). 
As distâncias estatísticas entre as estações de Pinhais e Curitiba e de Fernandes Pinheiro e Lapa são muito pequenas, o que pode levar à conclusão que o clima nestes locais é muito parecido, segundo os critérios (variáveis) utilizados nesta análise.

Quanto às áreas quentes, há uma separação das estações da parte norte do estado, acima e próximo ao Trópico de Capricórnio (232 $\left.7^{\prime} 09^{\prime \prime} \mathrm{S}\right)$ das estações ao sul do Trópico de Capricórnio (segundo corte da Figura 1). As estações de Apucarana, Bandeirantes, Londrina, Ibiporã, Bela Vista do Paraíso, Cianorte, Paranavaí, Umuarama, Cambará, Joaquim Távora e Jacarezinho são as representantes desta parte norte, sendo que a estação mais meridional deste grupo é Umuarama (23⒋ $4^{\prime} \mathrm{S}$ ).

As estações de Cambará, Joaquim Távora e Jacarezinho formam um subgrupo.

Dentre as estações quentes, abaixo do paralelo $23^{\circ} 44^{\prime} \mathrm{S}$, as estações da área litorânea se separam das demais, conforme seria esperado (terceiro corte, Figura 1).

$\mathrm{Na}$ área litorânea, Antonina e Guaraqueçaba se assemelham, enquanto a de Morretes se agrupou à estação de Paranaguá.
Dentre as estações de áreas mais quentes, abaixo do paralelo $23^{\circ} 44^{\prime}$ S e fora da área litorânea, podem-se visualizar nitidamente alguns grupos. Um mais central, formado por Campo Mourão, Nova Cantu, Telêmaco Borba e Cândido de Abreu. Outro grupo, de sudoeste, é formado por Quedas do Iguaçu, Francisco Beltrão, Laranjeiras do Sul e Pato Branco. Num outro grupo, das áreas baixas de sudoeste, têm-se as estações de São Miguel do Iguaçu, Planalto, Nova Cantu, Palotina, Guaíra e Foz do Iguaçu. As estações de Mauá da Serra e Apucarana estão localizadas mais no centro-norte do estado.

As estações de Telêmaco Borba e Cândido de Abreu, apesar de estarem no mesmo grupo das estações mais

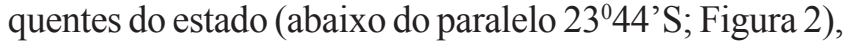
diferenciam-se do grande grupo por se posicionarem em maiores altitudes em relação a este e estarem situadas no Primeiro e Segundo Planaltos; enquanto as outras estão localizadas no Terceiro Planalto, distantes do efeito da continentalidade.

\section{Dendograma Método Ward, Distância Euclidiana}

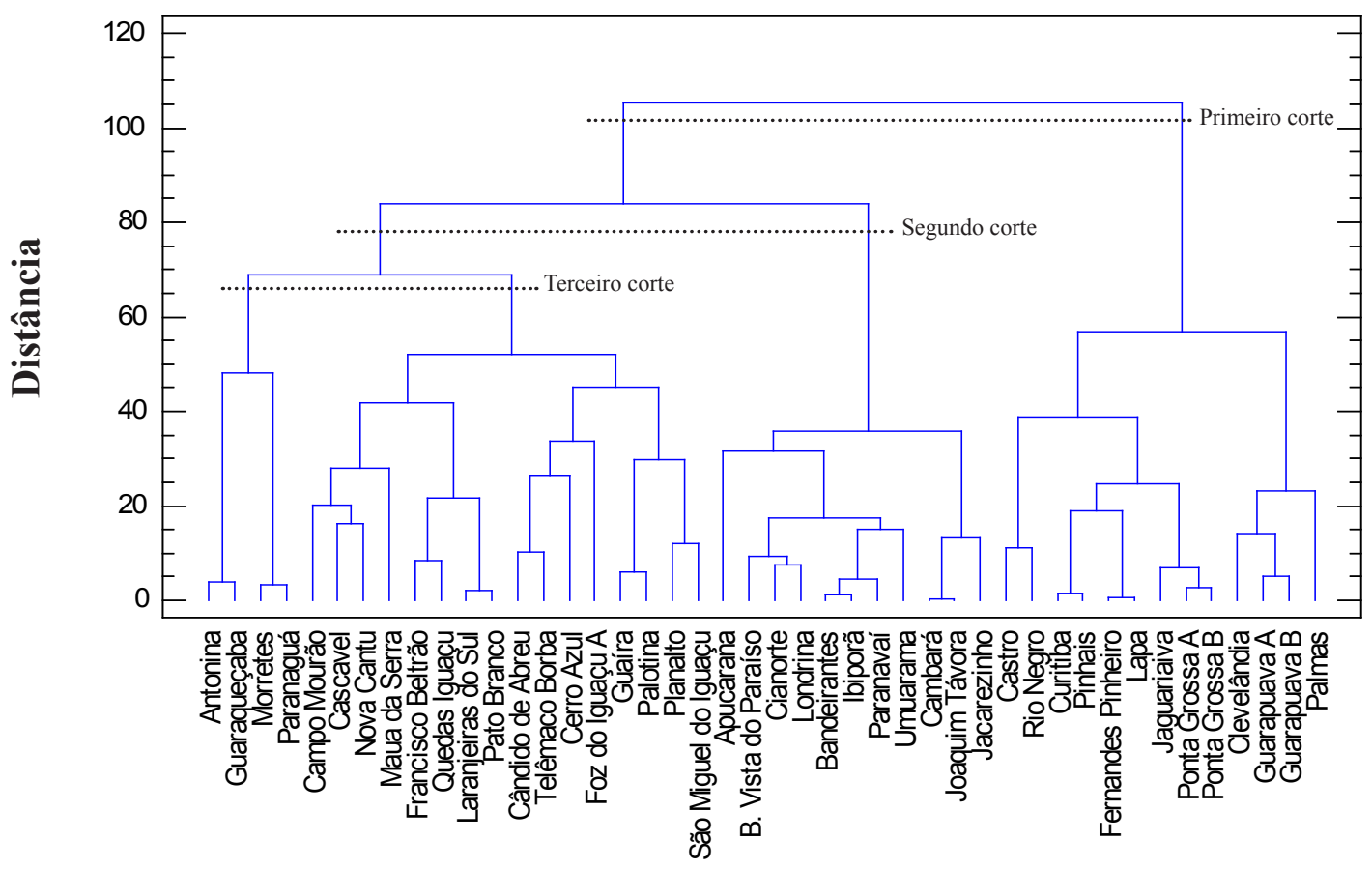

Figura 1. Dendrograma utilizando os dados completos das estações meteorológicas 
A estação de Cerro Azul, bem como a estação de Foz do Iguaçu, ambas em baixa altitude apresentam certa semelhança climática quanto à temperatura, mas grandes diferenças, especialmente quanto à precipitação, disponibilidade hídrica e localização geográfica. Isto se deve às diferenças geográficas existentes: enquanto o Município de Cerro Azul, a leste do estado, situa-se topograficamente encaixado no médio Vale do Ribeira e Foz do Iguaçu situa-se na ampla calha do Rio Paraná, extremo sudoeste do estado, área aberta às entradas de ar continental. Assim, as regiões destas duas estações devem ser diferenciadas das demais e entre elas.

\section{Mapa de unidades geoclimáticas}

Depois de localizadas todas as estações na carta hipsométrica e identificados os grupos, com apoio do dendrograma e do banco de dados, as unidades compostas pelos grupos foram delimitadas na carta hipsométrica, compondo o mapa de unidades geoclimáticas (Figura 2). Assim, este mapa foi confeccionado com o apoio da interpretação ambiental do dendrograma (Figuras 1 e 3), da carta hipsométrica, da carta fitogeográfica de Maack (1950), e pela observação das imagens de satélites meteorológicos. As áreas em branco neste mapa são áreas carentes de monitoramento climático.

\section{Construção da tabela de pertinência das unidades geoclimáticas}

A partir do mapa de unidades geoclimáticas, foi elaborada a tabela de pertinência (Tabela 2A e B). Nela, as tipologias são mostradas em grandes grupos, grupos, subgrupos e unidades para uma melhor compreensão da relação entre eles, tanto de pertinência, quanto de hierarquia. Em cada subgrupo e unidade há a caracterização climática, com dados provenientes do banco de dados (Tabela 1), para melhor caracterização dos mesmos. A estação escolhida para representar o grupo (em negrito) é a de monitoramento mais antigo.

$\mathrm{O}$ estado foi dividido em três grandes grupos, um representado pelas áreas mais frias, outro pelas áreas mais quentes e um terceiro pelas áreas do litoral (Tabela 2A e B). A primeira divisão das áreas frias (grupos 1.1 e 1.2) se refere às áreas com inverno muito rigoroso e com alta pluviosidade (1.1) e outra, com inverno acentuado e relativamente mais seco (1.2).
O grupo 1.1 pode ser dividido em três subgrupos. O subgrupo 1.1.1 é referente ao Planalto de Palmas e Guarapuava. Este subgrupo apresenta um inverno muito rigoroso, com incidência do maior número de geadas observadas por ano, situadas em elevadas altitudes, com alta pluviometria e grande disponibilidade hídrica. A estação de Guarapuava é a estação representante deste subgrupo. O subgrupo 1.1.2 representa as áreas intramontanas do Planalto de Guarapuava e o subgrupo 1.1.3 representa o reverso da Serra Geral, localizando-se predominantemente na porção oriental do Planalto de Guarapuava. Os subgrupos 1.1.2 e o 1.1.3 não apresentam estações meteorológicas e foram discriminados do subgrupo 1.1.1 devido a fatores de ordem geográfica.

O grupo 1.2 foi dividido em cinco subgrupos. $\mathrm{O}$ primeiro, 1.2.1, mais restrito geograficamente, tem como características uma grande amplitude térmica anual (ATA), grande quantidade de água disponível, baixa insolação e apresenta União da Vitória como estação representante. O subgrupo 1.2.2 localiza-se ao sul do Primeiro e Segundo Planaltos e tem como representante a estação de Curitiba, sendo locais, em geral, mais altos, mais frios e com alta umidade relativa em relação a outros subgrupos deste grupo. O 1.2.3 localiza-se na bacia do Alto Tibagi, Alto Ivaí e Alto Paranapanema, tendo como representantes as estações de Ponta Grossa e Jaguariaíva. Este subgrupo apresenta maior insolação, sendo, em média, mais quente que o anterior. O subgrupo 1.2.4 foi dividido em duas unidades. A unidade 1.2.4.1 tem como representante a estação de Castro, sendo um local alto e frio, mas de baixa insolação, e a unidade 1.2.4.2 não está representada por nenhuma estação e foi separada da unidade anterior por constituir uma borda do Segundo Planalto, sendo provavelmente um local mais frio e com maior pluviosidade devido às chuvas orográficas. O sub grupo 1.2.5 compreende as áreas elevadas da borda oriental do Planalto de Maracanã e não há estações representantes.

Quanto ao grande grupo 2, refere-se às áreas mais quentes, sendo composto de dois grandes subgrupos, um acima do paralelo $23^{\circ} 44^{\prime} \mathrm{S}(2.1)$ e outro abaixo deste paralelo (2.2). 


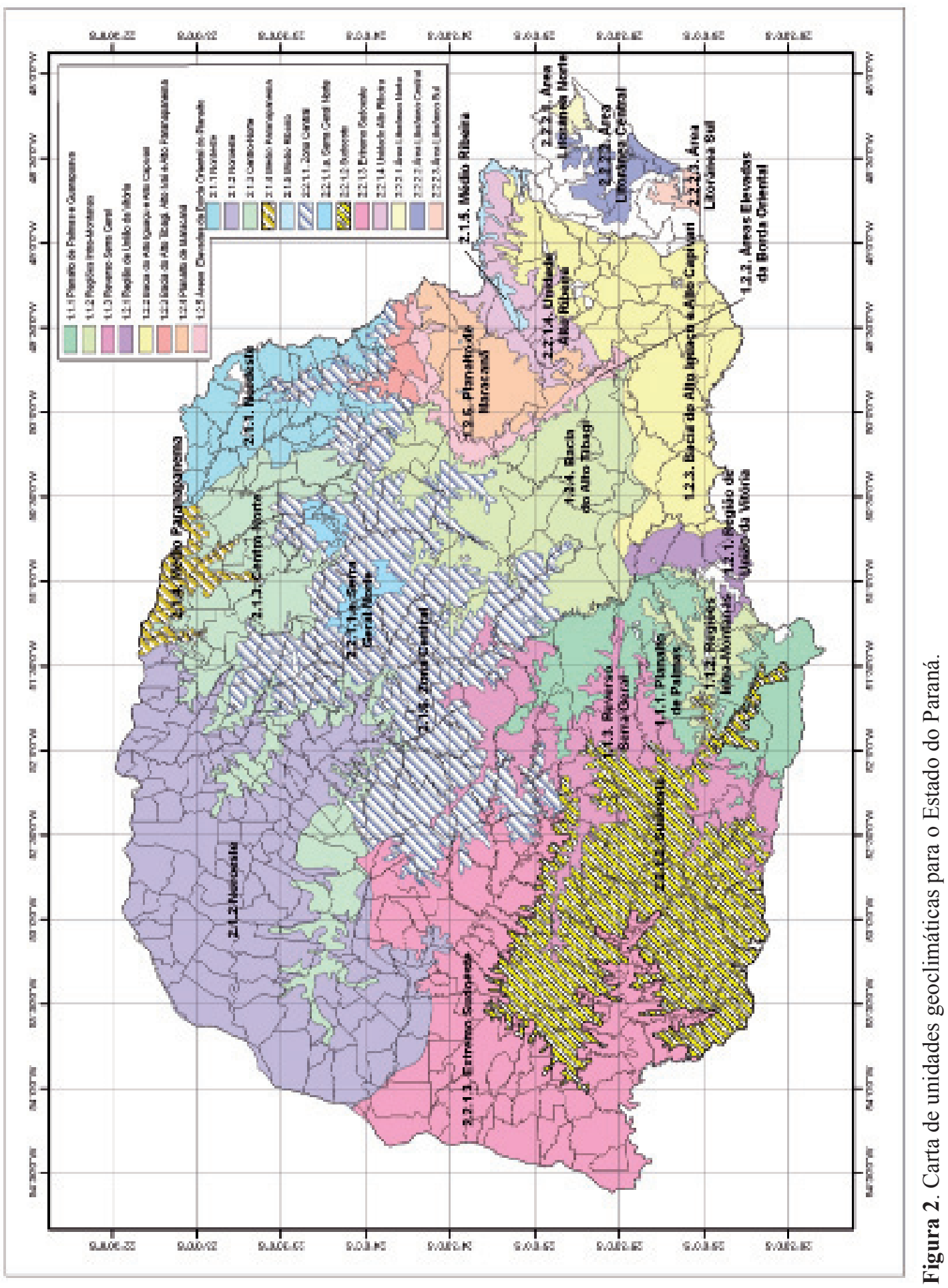


Dendograma

Método Ward, Distância Euclidiana

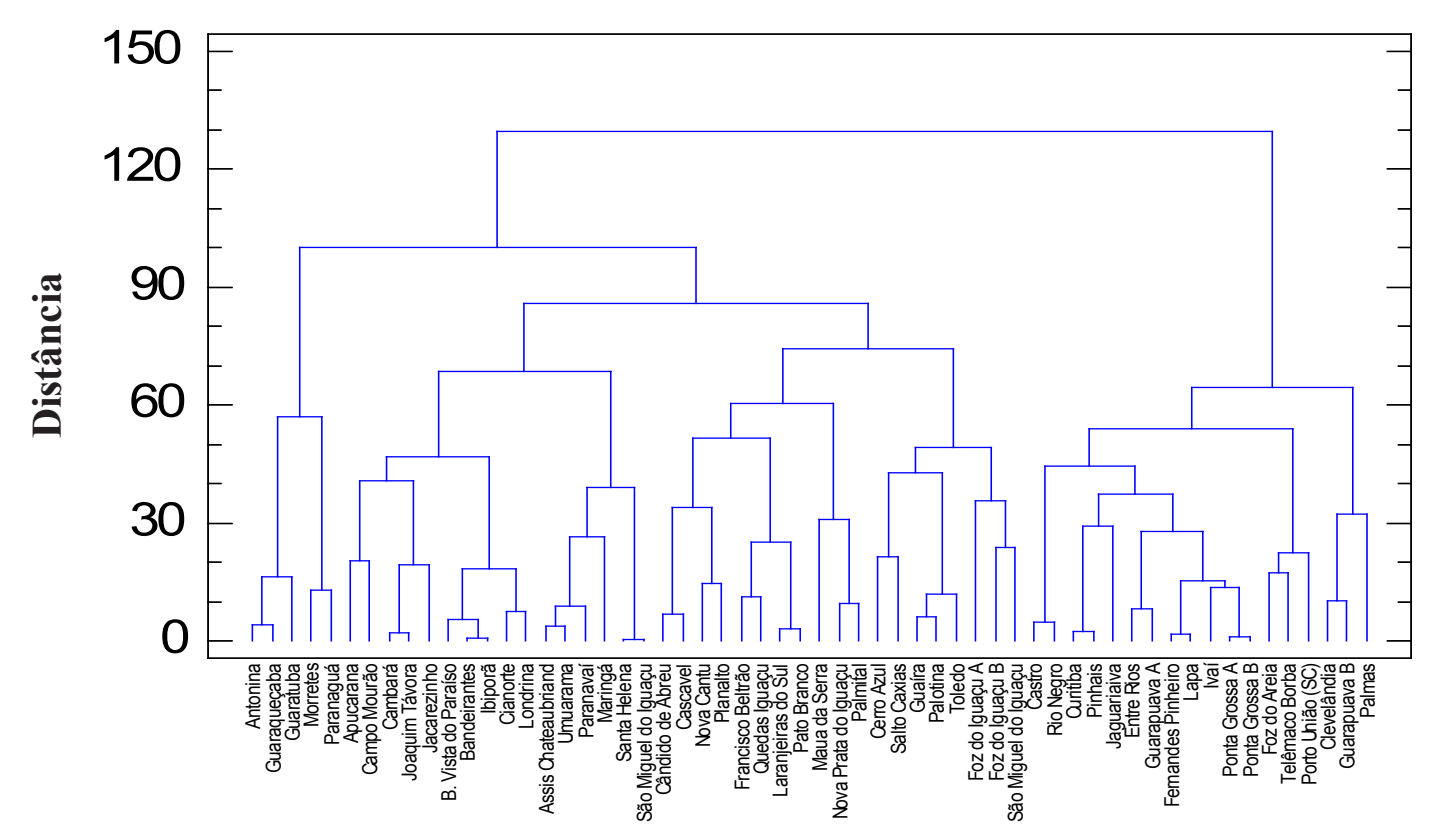

Figura 3. Análise de Cluster com todas as estações meteorológicas. Variáveis climáticas utilizadas: temperatura média das máximas anuais (TMMA), temperatura média das mínimas anuais (TMMI), temperatura mínima absoluta (TMIABS), temperatura máxima absoluta (TMAABS), temperatura média das médias anuais (TMME), amplitude térmica média anual (ATA), temperatura média anual de janeiro (TMJA), temperatura média anual de julho (TMJU), precipitação média anual (Pptação), trimestre mais seco (TMS), trimestre mais úmido (TMU), diferença entre trimestres (DET). 


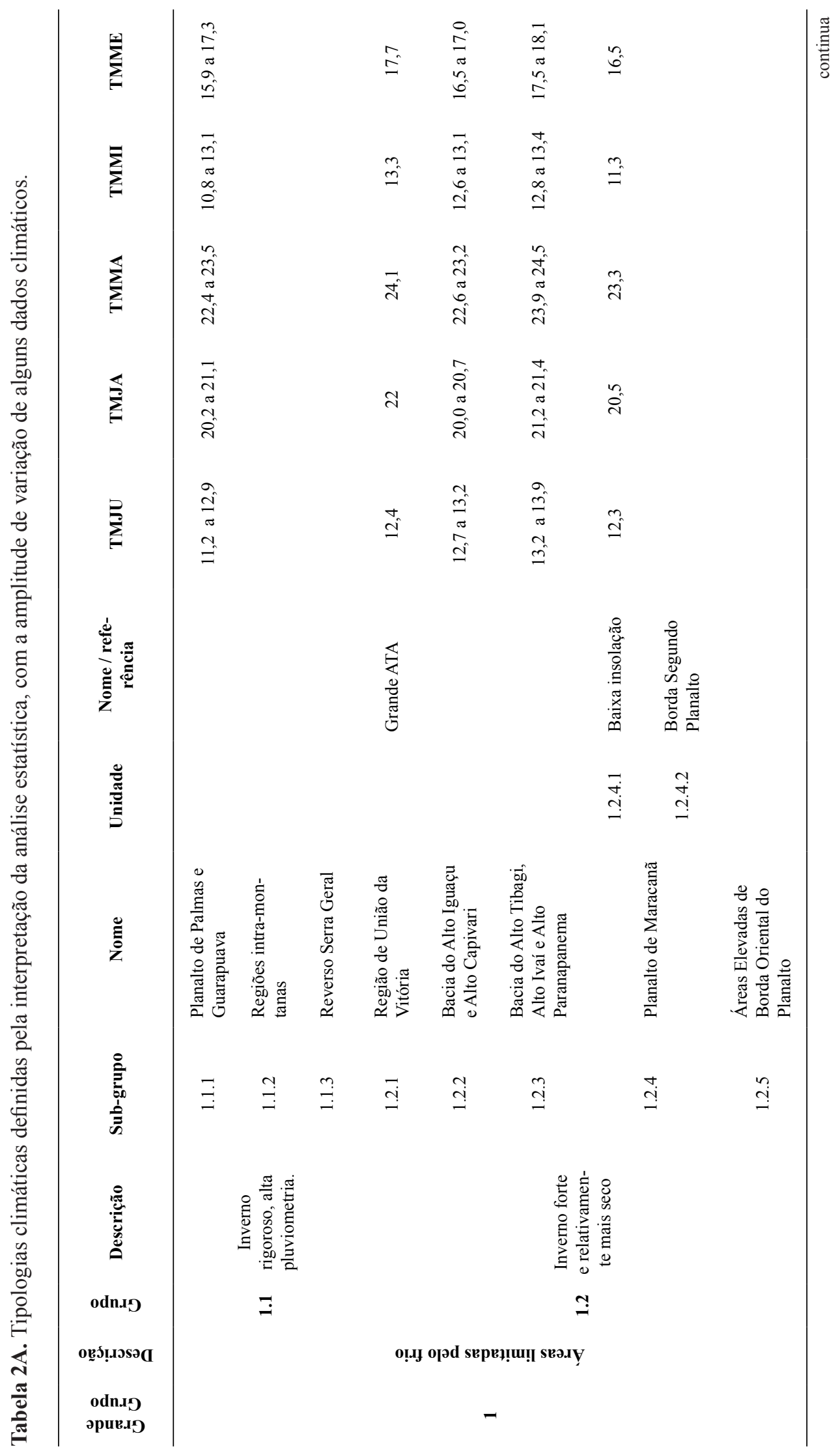




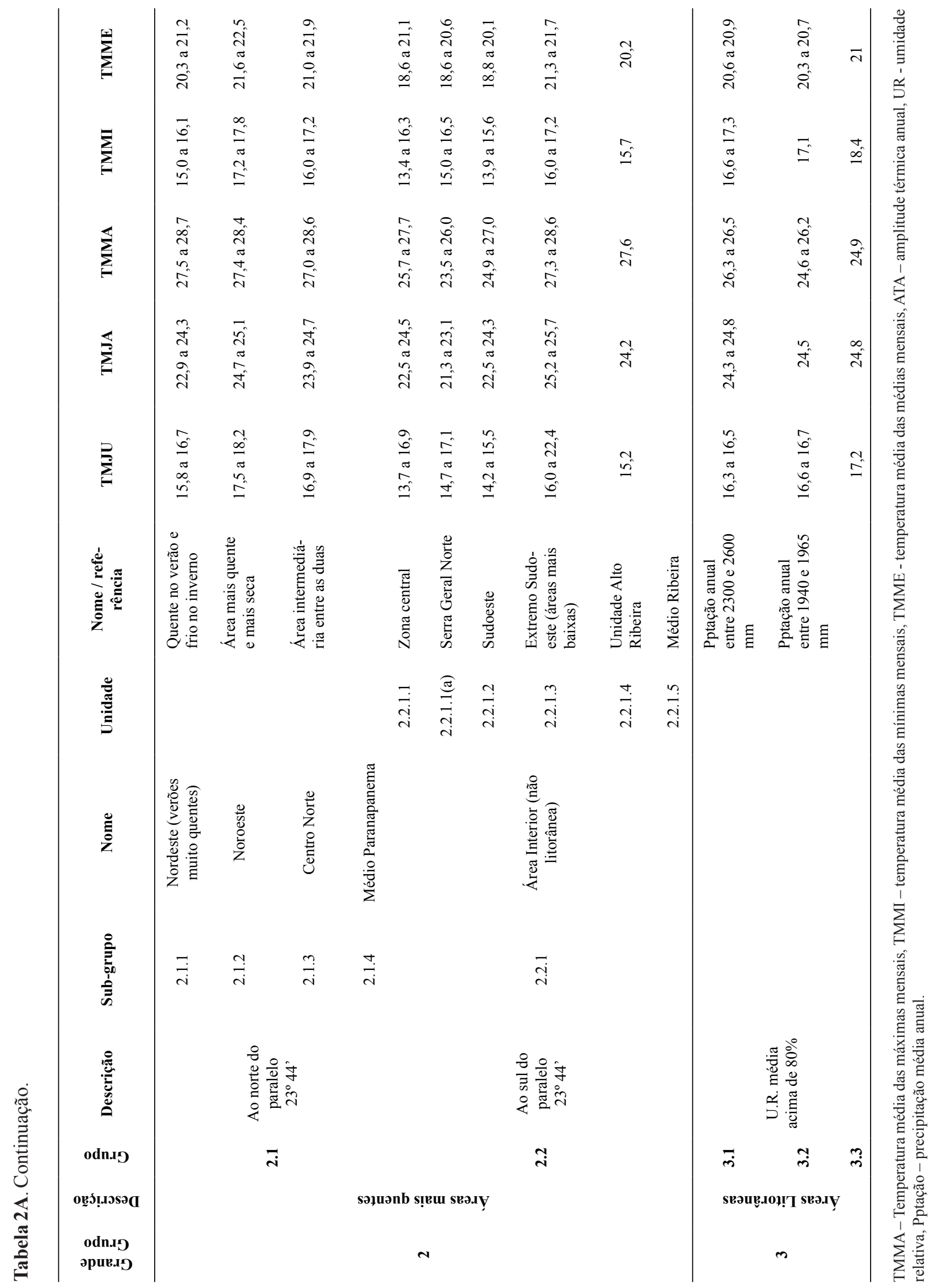




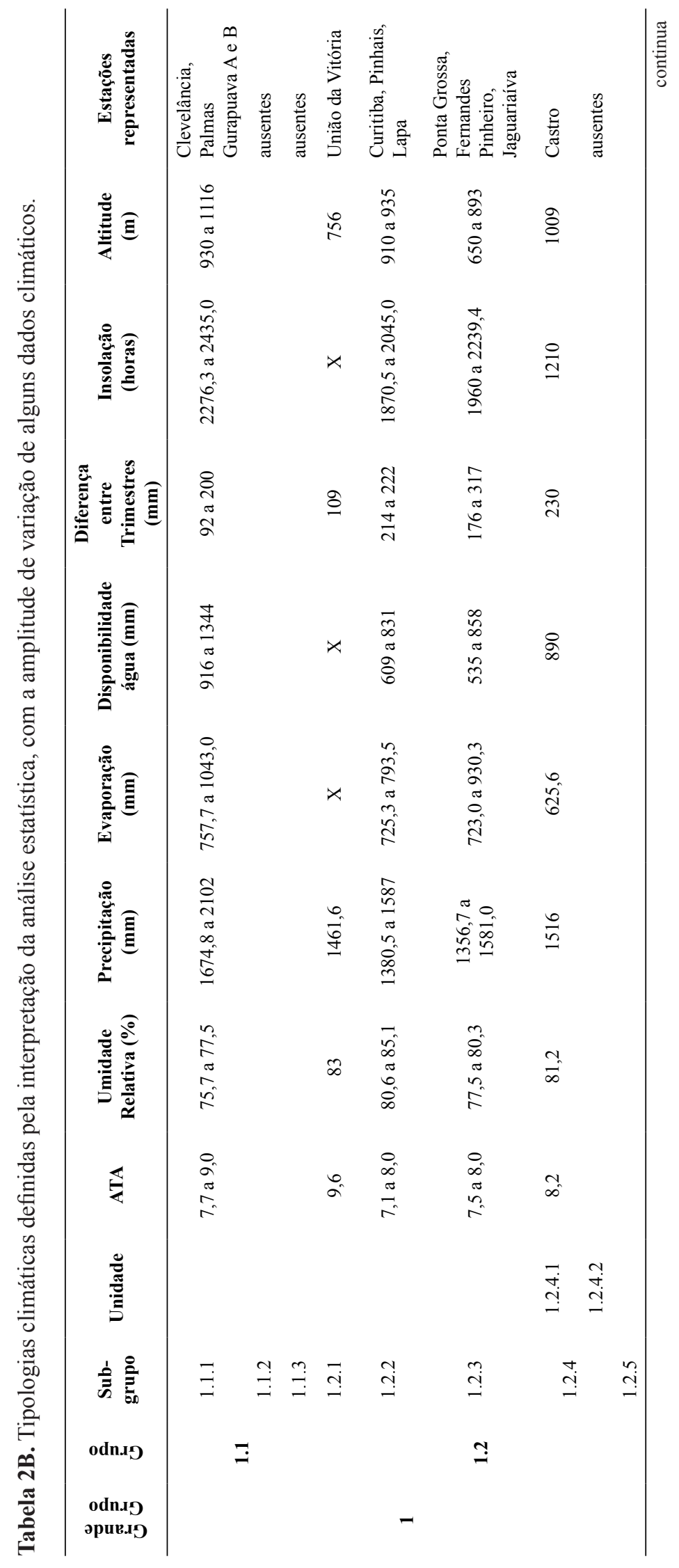




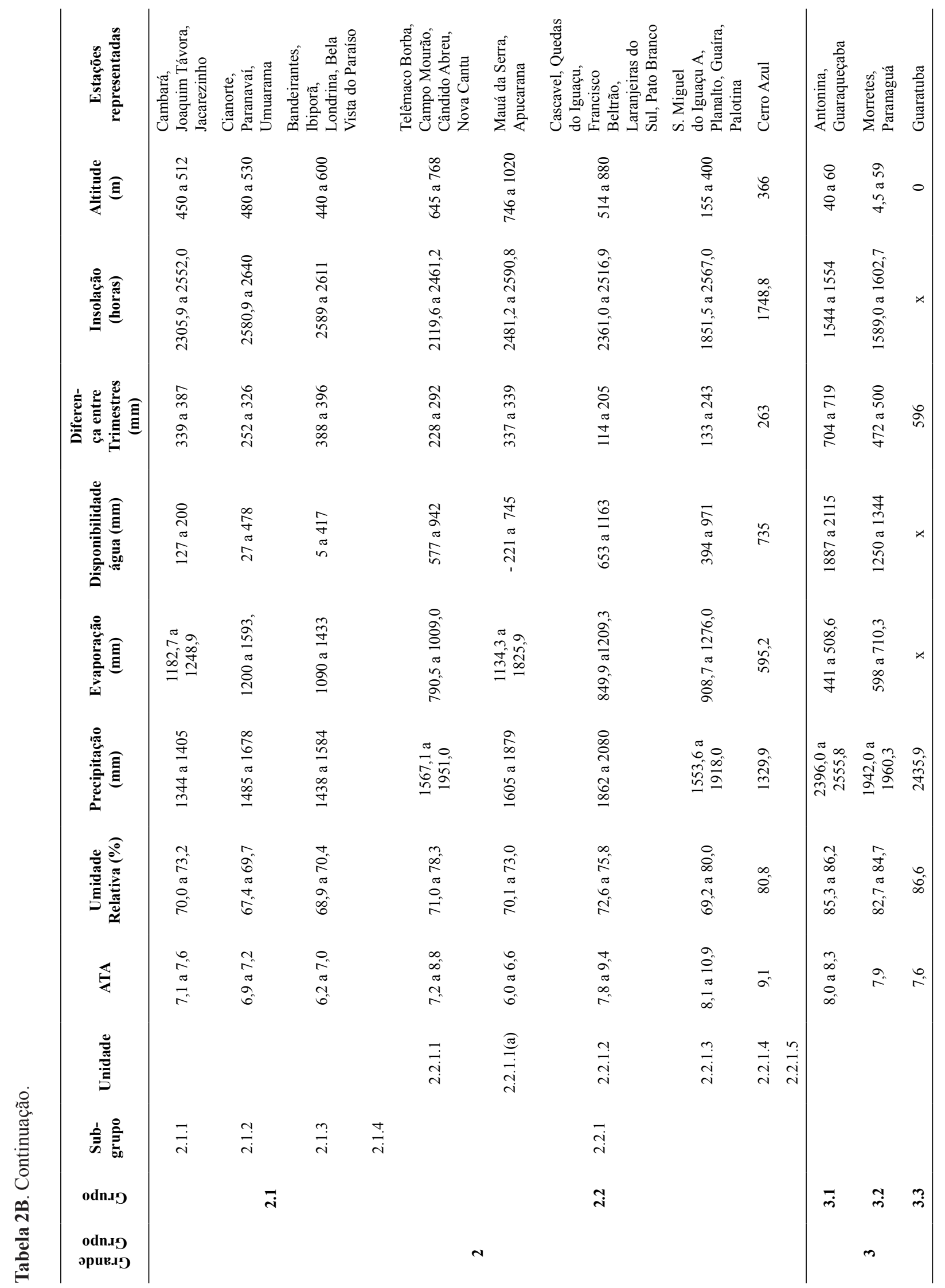


O subgrupo acima do paralelo $23^{\circ} 44^{\prime} \mathrm{S}$ foi divido em quatro subgrupos. O subgrupo localizado no extremo nordeste do estado (2.1.1) tem como representante a estação de Cambará, sendo caracterizada pelos verões quentes, umidade relativa entre $70 \%$ e $73 \%$, disponibilidade hídrica média anual entre $127 \mathrm{~mm}$ e $200 \mathrm{~mm}$, apresentando a menor média das temperaturas mínimas deste grupo $\left(15{ }^{\circ} \mathrm{C}\right.$ a $\left.16{ }^{\circ} \mathrm{C}\right)$ e menor média entre temperaturas médias $\left(20^{\circ} \mathrm{C}\right.$ a $\left.21^{\circ} \mathrm{C}\right)$. A unidade 2.1.3 está representada pela estação de Bela Vista do Paraíso, apresentando verões mais quentes do que na unidade 2.1.1, temperatura média anual entre $21{ }^{\circ} \mathrm{C}$ e $22{ }^{\circ} \mathrm{C}$, umidade relativa entre $69 \%$ e $71 \%$. Outra unidade (2.1.2) está localizada no extremo noroeste do estado, tendo como representante as estações de Cianorte e Umuarama, sendo caracterizada por apresentar invernos mais quentes, levando em consideração a temperatura média de julho $\left(17,5^{\circ} \mathrm{C}\right.$ a $\left.18,2^{\circ} \mathrm{C}\right)$, média das temperaturas médias entre $21,6{ }^{\circ} \mathrm{C}$ e $22,5^{\circ} \mathrm{C}$, maior mínima, entre $17^{\circ} \mathrm{Ce} 17,8^{\circ} \mathrm{C}$. Nesta unidade está situado um dos locais mais quentes do Paraná, que é Paranavaí. O subgrupo 2.1.4 (médio Paranapanema) está situado ao norte da unidade 2.1.3, e foi delimitado por apresentar continuidade climática com as estações do Estado de São Paulo.

O grupo 2.2 está abaixo do paralelo $23,44^{\circ} \mathrm{S}$ e está dividido em cinco unidades: na zona central do estado (2.2.1.1), no sudoeste (2.2.1.2), no extremo sudoeste (2.2.1.3), a Unidade Alto Ribeira (2.2.1.4) e Médio Ribeira (2.2.1.5).

A Zona Central do estado (2.2.1.1) constitui uma zona de transição entre as áreas frias do sul e as mais cálidas do norte, havendo a necessidade, para sua melhor caracterização, de um maior número de estações meteorológicas. A estação representativa é a de Campo Mourão. Esta unidade apresenta temperatura média anual entre $18,6{ }^{\circ} \mathrm{C}$ a $21,1{ }^{\circ} \mathrm{C}$, umidade relativa de $71 \%$ a $78 \%$, disponibilidade de água entre $577 \mathrm{~mm}$ e $942 \mathrm{~mm}$, temperatura média anual de julho entre $13,7^{\circ} \mathrm{C}$ e $16,9^{\circ} \mathrm{C}$ e temperatura média anual entre $18,6^{\circ} \mathrm{C}$ e $21,1^{\circ} \mathrm{C}$. Nesta unidade, foi diferenciada outra subunidade (2.2.1.1 a), que ocorre em locais de altitudes maiores e tem como representante a estação de Apucarana.

A unidade 2.2.1.2 localiza-se no sudoeste do estado e tem como representante as estações de Cascavel e Quedas do Iguaçu, apresenta temperatura média anual entre $19{ }^{\circ} \mathrm{C}$ e $20^{\circ} \mathrm{C}$, temperatura média anual de julho entre $14,2{ }^{\circ} \mathrm{C}$ e $15,5{ }^{\circ} \mathrm{C}$, chegando a ocorrer geadas frequentes. A disponibilidade de água é alta e a insolação também, sendo o intervalo da ATA entre $7,8^{\circ} \mathrm{C}$ e $9,4^{\circ} \mathrm{C}$. $\mathrm{Na}$ unidade 2.2.1.3 estão as áreas baixas do extremo sudoeste, de altitude entre $155 \mathrm{~mm}$ e $400 \mathrm{~m}$, com forte diferença entre trimestre mais seco e mais úmido e amplitude térmica entre $8,1^{\circ} \mathrm{C}$ e $10,9^{\circ} \mathrm{C}$, sendo as maiores registradas no estado e com grande número de geadas observadas. A estação representativa deste grupo é a de Guaíra. Esta unidade é a melhor representada no estado em termos de número de estações meteorológicas.

A unidade do Alto Ribeira (2.2.1.4) tem como representante uma única estação (Cerro Azul), evidenciando a carência de dados para o Vale do Ribeira, apresentando uma alta umidade relativa $(81 \%)$, baixa precipitação e baixa evaporação. A unidade 2.2.1.5 é a do Médio Ribeira e se diferencia em termos geoclimáticos da unidade 2.2.1.4, mas não há estação representante.

No grupo pertencente à área litorânea foram diferenciados três grupos distintos. O primeiro (3.1) está representado por Guaraqueçaba e tem como característica uma elevada precipitação $(2.390 \mathrm{~mm}$ a $2.550 \mathrm{~mm})$, baixa evaporação, com consequente grande quantidade de água disponível e ainda uma grande diferença entre trimestre mais seco e mais úmido (704 $\mathrm{mm}$ a $719 \mathrm{~mm}$ ). O segundo grupo (3.2) tem por representante a estação de Paranaguá, com precipitação média anual inferior à primeira unidade, entre $1.940 \mathrm{~mm}$ e $1.960 \mathrm{~mm}$, maior evaporação e menor disponibilidade de água. A terceira unidade (3.3) situa-se ao sul do litoral paranaense e tem como representante a estação de Guaratuba, que apresenta precipitação semelhante à unidade 3.1, mas com a temperatura média do mês de janeiro mais frio e de julho mais quente em relação a esta unidade (terral frio mais acentuado em Paranaguá).

Algumas considerações devem ser feitas quanto a este zoneamento. Dentro das unidades geoambientais pode haver grande diversidade climática devido a altitudes diferenciadas em relação à média e situações microclimáticas diversas: exposição de vertentes para o sul ou norte, zona de baixadas, calha de rios, corredores orográficos, efeitos de inversão térmica, ilhas de calor urbano, proximidades de espelhos d'agua, brisa de mar e terral, solos mais argilosos ou mais arenosos. Estas diferenças, em pequena escala, caso deste mapeamento, não são contempladas e podem significar fortes distorções climáticas comparado às estações representativas de cada unidade. Assim, estudos mais detalhados necessitam ser realizados para determinação 
climática das condições locais, ou mais específicas.

Durante a fase de elaboração de uma próxima versão deste zoneamento, devem ser analisadas as fases de vegetação das associações de solo constantes no Levantamento de Solos do Paraná (Embrapa, 1984), que apresenta observações efetuadas em campo sobre domínios vegetacionais, o que permite um ajuste mais detalhado dos limites das unidades homoclimáticas.

A metodologia utilizada neste trabalho poderia também ser aplicada a outras regiões, ou estados, desde que haja número suficiente de estações meteorológicas que possibilite a aplicação da análise estatística para separar grupos climáticos homogêneos.

Os resultados obtidos neste estudo também podem fornecer subsídios às relações entre as questões ambientais e aspectos climáticos e sanitários no Estado do Paraná e região Sul do Brasil, a exemplo de Mantovani et al. (2008).

\section{Considerações finais}

Pela interpretação dos dados metereológicos submetidos á Análise de Cluster, o Estado do Paraná foi dividido em dois grandes grupos: áreas mais quentes e áreas mais frias. Dentre as áreas quentes, as áreas litorâneas foram separadas das áreas continentais.

A tabela de pertinência, composta para este trabalho, apresenta uma grande utilização de ordem prática, pois possibilita alocar espécies para plantio nas áreas mais adequadas, desde que se conheçam suas exigências climáticas (temperatura mínima, média, resistência a geadas, déficit hídrico, etc).

A metodologia utilizada serviu plenamente ao propósito de agrupar estações similares. Entretanto, para que este processo seja bem sucedido, é essencial que haja uma base de dados climáticos ampla, com muitas estações e com monitoramento de, no mínimo, 10 anos.

Esta é uma primeira aproximação do zoneamento com a metodologia proposta. Este trabalho pode ser complementado, no futuro, com dados de outras estações instaladas no estado e outras informações, tais como irradiação solar, incidência de ventos, etc. Ele também poderá ser transformado em um zoneamento edafoclimático, com incorporação das informações sobre as principais classes de solos, profundidade efetiva, balanço hídrico, elementos fundamentais de serem conhecidos para o sucesso dos plantios florestais.

\section{Agradecimentos}

Os autores agradecem ao Simepar pelos dados enviados, sem os quais este trabalho não seria possível de ser realizado, e também ao Iapar, IAC, Suderhsa e Epagri, pelos dados climáticos utilizados neste trabalho. Agradecemos também aos pesquisadores Antonio Aparecido Carpanezzi e Marilice Cordeiro Garrastazú, da Embrapa Florestas, ao professor Anselmo Chaves Neto, do Departamento de Estatística da UFPR, a Itamar Adilson Moreira, meteorologista do Simepar, pelas valiosas colaborações, e também à estagiária Ana Paula Araujo Correa, pelo auxílio na atualização do banco de dados climáticos.

\section{Referências}

ANDRADE, L. A. de; REIS, M. das G. F.; REIS, G. G. dos; COSTA, L. M. da. Classificação ecológica do estado da Paraíba. Delimitação e caracterização de sub-regiões ecológicas a partir de variáveis biopedológicas. Revista Árvore, Viçosa, v. 24, n. 2, p. 207-214, 2000.

BERNARDES, L. R. M. Determinação de regiões pluviometricamente homogêneas no estado do Paraná, através de técnicas de análise multivariada. 1998. $136 \mathrm{f}$. Tese (Doutorado em Engenharia) - Escola Politécnica, Universidade de São Paulo, São Paulo.

CARPANEZZI, A. A. (Coord.). Zoneamento ecológico para plantios florestais no Estado do Paraná .Brasília, DF: EMBRAPA-DDT; Curitiba: EMBRAPA-CNPF, 1986. 89 p.(EMBRAPA-CNPF. Documentos, 17).

DINIZ, G.B. BERLATO, M.A., CLARKE, R. T., FONTANNA, D. C. Identificação de regiões homogêneas de temperaturas máxima e mínima no Rio Grande do Sul. Revista Brasileira de Agrometeorologia, Santa Maria, v. 11, n. 2, p. 303-312, 2003.

EMBRAPA. Serviço Nacional de Levantamento e Conservação de Solos. Levantamento de reconhecimento dos solos do Estado do Paraná. Londrina: EMBRAPA-SNLCS: IAPAR, 1984. 2 t. 791 p. (EMBRAPA-SNLCS. Boletim de Pesquisa, 27; IAPAR-Projeto Especial Levantamento de Solos. Boletim Técnico, 16). Convênio: SUDESUL-EMBRAPA-GOVERNO DO ESTADO DO PARANÁ: IAPAR.

EPAGRI (Florianopolis, SC). Zoneamento agroecologico e socioeconomico do Estado de Santa Catarina. Florianopolis, 2001. 1 CD-ROM.

FAO (Roma, Itália). Zonificación Agro-ecológica: guia general. Roma. 1997. 82p. (FAO. Soils Bulletin, 73). Disponível em: $<$ http://www.fao.org/docrep/W2962S/W2962S00.htm>. Acesso em: 28 fev. 2007.

FALVO, G.; RIZZI, N. E.; CHAVES NETO, A. Zoneamento da bacia hidrográfica do Rio Miringuava utilizando-se de técnicas de análises multivariada. Revista do Setor de Ciências Agrárias. Curitiba, v. 15, n. 2, p 15-32, 1996. 
FERREIRA, M. Escolha de Espécies Arbóreas para formação de maciços florestais. Documentos Florestais, Piracicaba, n. 7, p.115 , jan. 1990 .

FRITZSONS, E.; MANTOVANI, L. E. ; AGUIAR, A. V. Relação entre altitude e temperatura: uma contribuição ao zoneamento climático no estado do Paraná. Revista de Estudos Ambientais, v. 10, p. $40-48,2008 \mathrm{a}$

FRITZSONS, E.; CARPANEZZI, A. A.; MANTOVANI, L. E. Elaboração de um banco de dados climáticos para o Estado do Paraná. Colombo: Embrapa Florestas, 2008b. 1 CDROM. (Embrapa Florestas. Documentos, 168).

GOLFARI, L.; CASER, R. L.; MOURA, V. P. G. Zoneamento ecológico esquemático para o reflorestamento no Brasil: $2 \mathrm{a}$. aproximação. Belo Horizonte: Centro de Pesquisa Florestal da Região do Cerrado, 1978. 66 p.(PRODEPEF. Série técnica, 11).

IAPAR. Médias históricas em estações do Iapar. Disponível em: <http://www.iapar.br/modules/conteudo/conteudo.

php? conteudo=1070>. Acesso em: 12 ago. 2009.

INMET (Brasil). Normais climatológicas. Rio de Janeiro: Ministério da Agricultura, Escritório de Meteorologia, 1969. v. 4. $74 \mathrm{p}$.

INMET (Brasil). Normais climatológicas (1961-1990). Brasília, DF: Secretaria Nacional de Irrigação, Departamento Nacional de Meteorologia, 1992. 84 p.

KELLER FILHO, ASSAD, E. D., LIMA, P.R.S. de R. Regiões pluviometricamente homogêneas no Brasil. Pesquisa Agropecuária Brasileira, Brasília, v. 40, n. 4, p. 311-322, abr. 2005. .

MAACK, R. Mapa Fitogeográfico do Estado do Paraná. Curitiba, IBPTG, 1950.

MANTOVANI, L. E.; OLIVEIRA, H. H.; BATISTELLA, M. Cartografia ecológica da área de proteção ambiental de Descalvado, SP. In: III CONGRESSO DE ECOLOGIA DO BRASIL, 1994. Anais. Londrina. Resumos, 1994.

MANTOVANI, L. E. ; BRANCO, D. M. ; SILVA, A. C. G. A. E. ; HAKARI, Hideo. Geoenvironmental conditions of the Brazilian Southern Highlands and human water intake. In: INTERNATIONAL GEOLOGICAL CONGRESS, 33., 2008. Anais. Oslo. MGH-01. Earth and health - medical geology - Part 2. Oslo, 2008.
McNab. Ecological Subregions of the United States. 1996. Disponível em: $<$ http://www.fs.fed.us/land/pubs/ecoregions/ index $>$. Acesso em: 25/10/2010.

REIS, M. das G. F.; LEONARDO, A. de A.; REIS, G. G. dos.; SOUZA, L. de S. Classificação ecológica do Estado da Paraíba. 2. Delimitação e caracterização de regiões ecológicas a partir de variaveis climáticas. Revista Árvore, Viçosa, v. 23, n. 2, p.139149, abr./jun. 1999.

RICHÉ, G. R.; MANTOVANI, L. E. Análise Geoambiental aplicada a projetos integrados de desenvolvimento rural. In: CONGRESSO BRASILEIRO DE CIÊNCIA DO SOLO, 21., 1987, Campinas. Programa e Resumos. Anais, Campinas: Sociedade Brasileira de Ciência do Solo, 1987. p. 78-79.

SEAB. Governo lança programa florestal para produção de madeira no Paraná. Disponível em $<$ http://www.seab.pr.gov.br/ modules/noticias/article.php?storyid=2936> . Acesso em: $10 \mathrm{dez}$. 2007.

TRISTÃO, R. A.; REIS, M. das G. F.; COSTA, L. M. da; ASPIAZU, C. Classificação ecológica de uma área do Estado de Minas Gerais: um método biopedológico. Revista Árvore, Viçosa, v. 21, n. 2, p. 201-212, 1997.

UNAL, Y.; KINDAP, T.; KARACA, M. Redefining the climate zones of Turkey using cluster analysis. International Journal of Climatology, Istanbul, v. 23, p. 1045-1055, 2003.

VENKATESH, B; JOE, M. K. Identifications of homogeneous rainfall regimes in parts of western Ghats regions of Karnataka. Journal Earth System Science, India, n. 4., p 321-330, 2007.

WILLIAMS, C.L; HARGROVE, W.W.; LEIBMAN, M.; JAMES, D.E. Agro-ecoregionalization of Iowa using multivariate geographical clustering, Agriculture, Ecosystems and Environment. Disponível em: http://www.srs.fs.usda.gov/pubs/ja/ ja_williams011.pdf. Acesso: 4 de outubro de 2007.

Recebido em 21 de agosto de 2009 e aprovado em 27 de outubro de 2010 
